\title{
LEY DE GARANTÍAS Y PROTECCIÓN INTEGRAL DE LOS DERECHOS DE LA NIÑEZ Y LA ADOLESCENCIA: EL NIÑO, NIÑA Y ADOLESCENTE COMO EPICENTRO DEL SISTEMA
}

\author{
LAW OF GUARANTEES AND INTEGRAL PROTECTION \\ OF CHILDREN AND ADOLESCENTS: THE CHILD AND \\ ADOLESCENT AS EPICENTER OF THE SYSTEM
}

ISAAC RAVETLLAT BALLESTÉ*

\section{RESUMEN}

El presente estudio realiza un esfuerzo de sistematización de aquellos que consideramos están llamados a ser los principios y las bases sobre las que debe sustentarse una nueva realidad normativa que, de una vez por todas, nos permita superar la lectura decimonónica que, aún a día de hoy, pervive de la niñez y la adolescencia en nuestro sistema legal. Es necesario, sin lugar a dudas, abandonar actitudes paternalistas o caducas convenciones educativas en que los niños, niñas y adolescentes son contemplados todavía en función de lo que pueden llegar a ser - en el día de mañana - y no por lo que preguntan, sienten o necesitan en tiempo real.

Palabras clave: Derechos de la niñez y la adolescencia, Derecho de la persona, Interés superior del niño, Autonomía progresiva, Sistema público de protección, Convención sobre los Derechos del Niño.

\footnotetext{
*Abogado. Doctor y Magister en Derecho de Familia e Infancia por la Universidad de Barcelona (España). Profesor Asistente de la Facultad de Ciencias Jurídicas y Sociales de la Universidad de Talca. Director del Centro de Estudios sobre los Derechos de la Infancia y la Adolescencia (CEDIA) de la Universidad de Talca, Talca, Chile. Subcoordinador General de la Red de Universidades por la Infancia de Chile. Correo electrónico: iravetllat@utalca.cl. Código Orcid: https://orcid.org/00000003-3857-8150.
}

Artículo recibido el 16 de junio de 2020 y aceptado para su publicación el 16 de diciembre de 2020 . 


\section{ABSTRACT}

The present study makes an effort to systematize those that we consider are called to be the principles and the bases on which a new normative reality must be sustained that, once and for all, allows us to overcome the nineteenth-century reading that, even today, it survives from childhood and adolescence in our legal system. It is necessary, without a doubt, to abandon paternalistic attitudes or outdated educational conventions in which children and adolescents are still considered based on what they can become tomorrow - and not because of what they ask, feel or need in real time.

Keywords: Children and adolescents rights, Right of the person, Best interests of the child, Progressive autonomy, Public protection system, Convention on the Rights of the Child.

\section{INTRODUCCIÓN}

Prácticamente no existen en Chile estudios específicos que aborden de manera integral los motivos que expliquen o vengan a justificar el porqué de la falta sistémica en nuestro ordenamiento jurídico de una regulación con claro y nítido enfoque de derechos de la niñez. Y no nos estamos refiriendo con ello, que también, a la falencia histórica de una Ley de garantías y protección integral de los derechos de la niñez y la adolescencia que venga, por fin -treinta años después-, a traducir e incorporar de manera definitiva a nuestra normativa doméstica los principios y derechos dimanantes de la Convención sobre los Derechos del Niño-CDN, en adelante-, sino a una cuestión mucho más profunda, más transversal, que se extiende a cualquier ámbito o sector del sistema normativo chileno.

Ejemplos podemos encontrar muchos y de diversa índole. Partiendo de la visión de la incapacidad, como regla general, desde la que el Código civil construye las categorías proculeyanas del infante, impúber o menor adulto (artículo 26), ${ }^{1}$ que si bien es cierto fueron acuñadas para referirse a una protección patrimonial contractual de los niños, niñas y adolescentes, ${ }^{2}$

\footnotetext{
${ }^{1}$ Delgado, Buenaventura, Historia de la infancia, Ed. Ariel, Barcelona, 1998, pp. 45-46.

${ }^{2}$ BARCIA, Rodrigo, "La capacidad extrapatrimonial de los niños y adolescentes conforme a sus condiciones de madurez", Ius et Praxis, 2013, Vol. 19, N², p. 5.
} 
ello no ha sido óbice para que, ante el silencio del legislador chileno acerca de la procedencia o no de la representación legal en materias relacionadas con aspectos de cohorte más bien extrapatrimonial -derechos de la personalidad ${ }^{3}$-, esa percepción de la niñez - como un ser incapaz y absolutamente dependiente- se haya expandido más allá de los límites para los que originariamente estuvo pensada. En efecto, el Código de Andrés Bello, de consabida influencia francesa por lo que a estas cuestiones se refiere -apartándose con ello de las tesis más propias del Derecho germánico-, optó, desde sus orígenes, por no estipular en su articulado una barrera cronológica que determinase o presumiera la adquisición de la capacidad natural ${ }^{4}$-aquella calificada como la edad de la razón- ${ }^{5}$ circunstancia ésta que trajo como consecuencia una patrimonialización, si se nos permite la expresión, de la cosmovisión civil de las personas menores de edad.

Asimismo, otras tantas leyes especiales llamadas a desarrollar derechos específicos que afectan de manera importante el devenir diario de las personas -también a las menores de edad-, como podrían ser la Ley $\mathrm{N}^{\circ}$. 20.584 , de 24 de abril de 2012, reguladora de los derechos y deberes que tienen las personas en relación con acciones vinculadas a su atención en salud; ${ }^{6}$ la Ley $\mathrm{N}^{\circ} 19.628$, de 28 de agosto de 1999, de Protección a la vida

\footnotetext{
${ }^{3}$ LATHROP, Fabiola, "El derecho a la imagen de niños, niñas y adolescentes en Chile. Una mirada crítica a la luz del Derecho Internacional de los Derechos Humanos y de los estatutos normativos iberoamericanos de protección integral de la infancia y la adolescencia", Revista Chilena de Derecho, 2013, Vol. 40, N 3, p. 943.

${ }^{4}$ Barcia, Rodrigo, "Derechos fundamentales y autonomía progresiva de la infancia", en: LePIN, C.; Gómez de la Torre, M. (coords.), Estudios de Derecho Familiar I, Thomson Reuters, Santiago, 2016, p. 218, sostiene que ya en el Código de Bello, en su versión original, se entendía que la patria potestad no operaba respecto de lo que hoy denominamos como derechos de la personalidad. Así, no se admitía la representación legal para contraer matrimonio a nombre del hijo/a, reconocer a un nieto, testar por el hijo(a), etc.

${ }^{5}$ RAVETLlat, Isaac, "Responsabilidad negocial de los actos realizados por personas impúberes: especial referencia a los actos relativos a bienes o servicios propios de su edad, de acuerdo con los usos sociales", en: Barría, M. (Coord.), Estudios de Derecho Civil XI, Thomson Reuters, Santiago, 2016, pp. 213-224.

${ }^{6}$ Parra, Darío; RavetLlat, Isaac, "El consentimiento informado de las personas menores de edad en el ámbito de la salud", Ius et Praxis, 2019, Año 25, N 3, pp. 235-240; PARRA, Darío, "El consentimiento informado de niños, niñas y adolescentes en el ámbito sanitario", en: DomínguEz, C. (Coord.), Estudios de Derecho de Familia III, Thomson Reuters, Santiago, 2018, pp. 331-349; Galán, Julio César, Responsabilidad civil médica, Civitas, Cizur Menor, 2016, pp. 621 y ss.; León, Francisco, "Información y consentimiento informado de menores de edad en Chile", Revista Chilena de Pediatría, 2012, Vol. 83, №. 2, 2012, pp. 113-116; VARAS, Juan Andrés, "Decisiones vitales y representación parental: fundamento y límites", en: Departamento de Derecho Privado de la Universidad de Concepción (Coords.), Estudios de Derecho Civil IV, Legal Publishing, Santiago, 2010, pp. 337-356.
} 
privada; ${ }^{7}$ la Ley $\mathrm{N}^{\circ}$ 20.500, de 16 de febrero de 2011, sobre asociaciones y participación ciudadana en la gestión pública; ${ }^{8}$ y la Ley $\mathrm{N}^{\circ} .21 .120$, de 10 de diciembre de 2019, de identidad de género, ${ }^{9}$ por citar algunas de las más relevantes, no contienen mención alguna, o de hacerlo como en el caso de esta última con una visión absolutamente restrictiva, acerca de si niños, niñas y adolescentes, más allá de la titularidad de derechos -que pareciera estar fuera de toda duda-, ostentan también, atendiendo siempre a su edad y estado de madurez, capacidad de ejercicio autónomo de los mismos. Y así podríamos seguir con un sin número más de cuerpos legales que parecen olvidarse, o invisibilizar si se prefiere, a los niños, niñas y adolescentes, tales como, la propia Constitución Política de la República, al excluir en su artículo 13 a las personas que no hayan alcanzado aún los dieciocho años de edad del concepto de ciudadanía; o la Ley $\mathrm{N}^{\circ} 19.968$, de 30 de agosto de 2004, que crea los Tribunales de Familia, cuando al enumerar en su artículo 105 los principios que deben regir los procesos de mediación familiar, al referirse al principio del interés superior del niño/a (apartado e.), lo hace partiendo de la base de la exclusión -como si esa debiera ser la regla general a seguir- de las personas menores de edad de las sesiones de este mecanismo alternativo de gestión de conflictos. ${ }^{10}$

${ }^{7}$ RiziK, Lucía, "La responsabilidad parental y las nuevas tecnologías de la información y la comunicación", en: Mondaca, A.; Aedo, C. (Coords.), Estudios de Derecho de Familia IV, Thomson Reuters, Santiago, 2019, pp. 443-460; LARRAín, Cristián, "Actos y contratos sobre el derecho a la imagen en el ordenamiento chileno (con referencia al derecho comparado)", Revista de Derecho (Valdivia), 2017, Vol. 30, N 1, pp. 53-76; Herrera, Paloma, "El derecho a la vida privada y las redes sociales en Chile", Revista Chilena de Derecho y Tecnología, 2016, Vol. 5, N 1, pp. 87-112; Donoso, Lorena, "El tratamiento de los datos personales en el sector de la educación", en: ArRIETA, R.; Reusser, C. (Coords.), Chile y la protección de datos personales: ¿están en crisis nuestros derechos fundamentales?, Ediciones Universidad Diego Portales, Santiago, 2009, pp. 57-79; y Jervis, Paula, "Derechos del titular de datos y habeas data en la Ley 19.628", Revista Chilena de Derecho Informático, 2003, № 2, pp. 19-33.

${ }^{8}$ RaVEtLlat, Isaac, "El derecho de asociación de niños, niñas y adolescentes", en: Moreno, A. y Schiele, C. (ed.), Pensamiento Jurídico Central, Volumen 2, Tirant lo Blanch, Valencia, 2019, pp. 236-257.

${ }^{9}$ Gauché, Ximena; Lovera, Domingo, "Identidad de género de niños, niñas y adolescentes: Una cuestión de derechos", Ius et Praxis, 2019, Año 25, N² 2, pp. 376-384; RavetLlat, Isaac, "Igual de diferentes: la identidad de género de niñas, niños y adolescentes en Chile", Ius et Praxis, 2018, Año 24 , $\mathrm{N}^{\circ}$ 1, pp. 422-427; y ESPEJO, Nicolás; LATHROP, Fabiola, "Identidad de género, relaciones familiares y derechos de niños, niñas y adolescentes. Comentarios al Proyecto de Ley que reconoce y da protección al derecho a la identidad de género", Revista de Derecho U. Católica del Norte, 2015, Vol. 22, № 2, pp.411-415.

${ }^{10}$ RaVETLlat, Isaac, "El interés superior del niño/a en los procesos de mediación familiar: Análisis de la realidad chilena", en: CÉsPedes, C. (Dir.), Estudios de Derecho Privado, Thomson Reuters, Santiago, 2019, pp. 11-15; GonZÁLEZ, Isabel, "Mediación y solución colaborativa de conflictos familiares. Participación del niño en la solución colaborativa de los conflictos de su familia", Revista Chilena de 
A nuestro entender, algunas de las razones que dilucidan esta falta de visibilización generalizada de la niñez y la adolescencia de nuestro ordenamiento jurídico, las encontramos en la misma evolución y construcción sociojurídica de la categoría infancia. En este sentido, debemos tener presente que la mentada noción no adquiere carta de naturaleza propia hasta fechas relativamente recientes, habiéndose circunscrito tradicionalmente su escaso y deficiente tratamiento normativo exclusivamente al ámbito del Derecho de Familia. Efectivamente, desde esta perspectiva clásica del Derecho de Familia, el niño y la niña únicamente son considerados con relación a su rol de hijo e hija, respectivamente, pero rara vez son contemplados como seres protagónicos que presentan sus propios anhelos, deseos e intereses. ${ }^{11}$

Por otra parte, este paradigma clásico al que hacíamos referencia en el párrafo anterior, vino a considerar a los niños y las niñas como un objeto (pasivo) digno de protección, reflejando con ello un claro carácter tutelar y paternalista.

El cambio de modelo, denominado de la minoridad, imperante hasta fines del siglo XX, se produjo en 1989, con la aprobación de la CDN. La misma vino a considerar a los niños, niñas y adolescentes como sujetos titulares de derechos, lo que supuso un claro antes y después para este grupo poblacional. La minoría de edad de la persona deja, por tanto, de comportar, a priori y per se, una negación de su capacidad volitiva o cognitiva; y el Estado debe, en todo caso, garantizar sus derechos y libertades.

Pues bien, es en este contexto poco proclive para la niñez y la adolescencia, y sus derechos, en el que se enmarca el presente estudio de sistematización de aquellos que consideramos están llamados a ser los principios y las bases sobre las que debiera sustentarse una nueva realidad normativa que, de una vez por todas, nos permitiera superar la lectura decimonónica que, aún a día de hoy, pervive de la niñez en nuestro sistema legal. Es necesario, sin lugar a dudas, abandonar actitudes paternalistas o caducas convenciones educativas en que los niños, niñas y adolescentes son contemplados todavía en función de lo que pueden llegar a ser -en el día de mañana- y no por lo que preguntan, sienten o necesitan en tiempo real. ${ }^{12}$

Derecho de Familia, 2020, Vol. 2, p. 272; VArgas, Macarena; Correa, Paula, "La voz de los niños en la justicia de familia de Chile”, Ius et Praxis, 2011, Año 17, N 1, pp. 190-193.

${ }^{11}$ Villagrasa, Carlos, "El derecho de la persona menor de edad hacia una disciplina autónoma desde el Derecho Civil", en: CABedo, V.; RavetLlat, I. (Coords.), Comentarios sobre las leyes de reforma del sistema de protección a la infancia y la adolescencia, Tirant lo Blanch, Valencia, 2016, pp. 23-48.

${ }^{12}$ JACQARD, Albert, ¿Una educación sin autoridad ni sanción?, Paidós, Barcelona, 2004, p. 21. 
En definitiva, cuando los niños, niñas y adolescentes adquieren protagonismo y perceptibilidad en la construcción de sus entornos cotidianos de vida, éstos mutan, se alteran, se hacen más democráticos, humanos, accesibles, acogedores y hasta incluso amables. ${ }^{13}$

\section{MODERNIZACIÓN LEGISLATIVA, SEGURIDAD JURÍDICA E INTE- GRALIDAD DE LA NORMA}

En 2021 se cumplen 31 años desde que en 1990 Chile ratificó la CDN (1989), y asumió como Estado, adoptar las medidas administrativas, legislativas y de otra índole que fueran necesarias para dar efectividad a los derechos reconocidos en el citado acuerdo internacional.

La Convención supera, tal y como avanzábamos en el apartado anterior, la concepción tutelar -teoría de la minoridad- de los niños, niñas y adolescentes que imperaba antes de su aprobación y entrada en vigor. De este modo, reconoce a las personas menores de edad como legítimos titulares de los derechos y libertades, así como de las responsabilidades aparejadas, que los pactos internacionales atribuyen a todo individuo, estableciendo que su desarrollo integral debe ser protegido de un modo preferente. ${ }^{14}$ Asimismo, concibe al niño, niña y adolescente como un individuo capaz -más allá de la simple titularidad- de gozar y ejercer derechos por sí mismo, en consonancia con la evolución de sus facultades. ${ }^{15}$

Pues bien, transcurridos esos treinta y un años, la acción legislativa del Estado chileno en materia de derechos y protección de la infancia y la adolescencia sigue caracterizándose por responder a una superposición progresiva de estratos normativos con derogación o desplazamiento parcial de los asentados previamente. Esto ha llevado a una situación de coexistencia en el tiempo de una multiplicidad de estatutos dispositivos que complica en

\footnotetext{
${ }^{13}$ Escobar, Margarita, "La participación ciudadana en Paraguay: análisis a partir de la transición democrática”, Revista Internacional de Investigación en Ciencias Sociales, 2012, Vol. 8, №. 1, p. 121.

${ }^{14}$ En este mismo sentido tomar en consideración lo estipulado por la Corte Interamericana de Derechos Humanos en dos importantes Opiniones Consultivas: la OC-21/14 de 19 de agosto de 2014. Serie A No. 19; y la OC-24/17 de 24 de noviembre de 2017.

${ }^{15}$ Véase el Mensaje del Proyecto de Ley, actualmente en segundo trámite constitucional. Documento: "Mensaje de S.E. la Presidenta de la República con que inicia un Proyecto de Ley de Sistema de Garantías de los Derechos de la Niñez", Boletín № 10.315-18, Cámara de Diputados, Valparaíso, 24 de septiembre de 2015, 39 pp., estado de tramitación legislativa disponible en línea: https://www. camara.cl/legislacion/ProyectosDeLey/tramitacion.aspx?prmID=10729\&prmBoletin=10315-18.
} 
gran medida la comprensión global de la materia. ${ }^{16}$ Así, en un contexto como el descrito, el nuevo marco normativo en el que se está pensado debiera venir a refundir parte de las instituciones ya existentes, así como a ordenar y clarificar este sector del ordenamiento jurídico, dotándolo de una mayor precisión y seguridad, a la par que contener un estatuto sistematizado de derechos y responsabilidades de (todos) los niños, niñas y adolescentes. ${ }^{17}$

Además, el hecho de vivir en una sociedad aceleradamente cambiante hace que sea del todo imprescindible adaptar los marcos legales a las nuevas circunstancias y sensibilidades de nuestro entorno sociocultural. Por ende, el nuevo texto normativo debe dar respuesta a la diversidad de cuestiones que se plantean en torno a la infancia y la adolescencia del siglo XXI.

De esta suerte, la proyectada Ley de Garantías y Protección Integral de los Derechos de la Niñez y la Adolescencia está llamada a significar un cambio radical en cuanto al tratamiento de los niños, niñas y adolescentes en el Estado chileno. Por vez primera, nuestro ordenamiento jurídico debe ofrecernos una imagen global de la infancia y la adolescencia. Efectivamente, con la promulgación de este nuevo cuerpo legal debiera darse respuesta a las necesidades de todos los niños, niñas y adolescentes como grupo social, como colectivo de ciudadanos - con independencia de la categorización que el vigente texto constitucional otorga al concepto- que presenta sus propios anhelos e inquietudes, y no cometer el error de sólo limitarse, como ha venido sucediendo hasta la fecha-Ley $\mathrm{N}^{\circ}$. 16.618, de 8 de marzo de 1967, Ley de Menores-, a las personas menores de edad en situación de riesgo o peligro social.

Por lo tanto, además de los derechos de supervivencia, el venidero modelo normativo también ha de incorporar todo el abanico de derechos civiles y políticos, así como los económicos, sociales y culturales - incluidos, por supuesto, los medioambientales - de la infancia y la adolescencia, sin establecer ningún tipo de relación jerárquica entre ellos. Todos deben

${ }^{16}$ El Estado chileno, tal y como se encargó de recordarnos el propio Comité de los Derechos del Niño en sus recomendaciones finales tras el examen de los informes periódicos cuarto y quinto, de octubre de 2015, está claramente al debe en esta cuestión. En este sentido el Comité ginebrino expresa su preocupación por la falta de una ley de protección integral de todos los niños y niñas. Así como lamenta que no hayan tenido éxito los intentos realizados en 2005 y 2012 para cambiar tal situación. Comité de los Derechos del NiÑo, Observaciones finales. Examen de los informes periódicos cuarto y quinto presentados por el Estado Chileno, 30 de octubre de 2015, Documento CRC/C/CHL/CO/4-5, párr. 8-9.

${ }^{17}$ Domínguez, Carmen, “Autonomía en materia de niñez: Tensiones y perspectivas”, en: BARRíA, M. (coord.), Estudios de Derecho Civil XI, Thomson Reuters, Santiago, pp. 106-108. 
situarse, pues, al mismo nivel, sin que ninguno ostente mayor relevancia o destaque por encima del resto. Ello sin olvidar que todos los derechos, tanto los de supervivencia como los de participación se complementan, son indivisibles, en otras palabras, se asisten y apoyan mutuamente. ${ }^{18}$

En suma, la Ley debe ver la luz con una inequívoca vocación de universalidad que aporte al ordenamiento jurídico chileno una mayor claridad y unidad, al tiempo que facilite una localización más rápida del derecho aplicable en cada momento y refuerce la seguridad jurídica. Es por ese motivo que ha de reunir -como así parece realizar el Proyecto de Ley- en un único instrumento legal tanto la regulación destinada al niño, niña y adolescente en general, en la que se establecen los principios rectores y derechos reconocidos a todas las personas menores de edad residentes en Chile, con independencia de su estatuto administrativo, como la destinada a fijar las bases - dejando para otro cuerpo legal el desarrollo detallado del modelo- del sistema de protección de niños, niñas y adolescentes que se encuentren en una particular situación de vulnerabilidad, para aquellos casos en que los mecanismos sociales de prevención no hayan resultado suficientes y se hayan generado situaciones de riesgo o peligro que deban ser paliadas con las necesarias medidas -subsidiarias en todo caso- de intervención pública, a fin de garantizar que tales circunstancias no se traduzcan en perjuicios irreparables para el niño, niña o adolescente.

\section{MODELO ORDENADO DE RECEPCIÓN DE LOS PRINCIPIOS $Y$ DERECHOS DIMANANTES DE LA CONVENCIÓN SOBRE LOS DERECHOS DEL NIÑO}

Para delimitar cuál es la mejor opción para desarrollar en el ámbito doméstico chileno los principios y derechos contenidos en el articulado de la CDN, debemos referirnos, previamente, a cuáles son los diferentes modelos o sistemas que existen en derecho comparado para llevar a cabo dicha recepción. Una vez realizado lo anterior, estaremos en predisposición de valorar cuál de ellos consideramos es el que mejor se condice con nuestro ordenamiento jurídico. En este sentido, podemos distinguir tres grandes

\footnotetext{
${ }^{18}$ Cots, Jordi, "Los antecedentes de la Convención. Síntesis de un logro", en: Villagrasa, C.; RavetLlat, I. (coords.), El desarrollo de la Convención sobre los Derechos del Niño en España, Bosch, Barcelona, 2006, pp. 35-36.
} 
alternativas. ${ }^{19}$

En primer término, encontramos un grupo de Leyes de infancia partidarias de una racionalización y optimización del sistema, que nos muestran abiertamente su reticencia y disconformidad en la que entienden como una innecesaria reiteración de contenidos meramente declarativos. Así, se considera que aquellas normas que se limitan a transcribir, de manera casi literal, el estatuto jurídico de los niños, niñas y adolescentes ya recogido en disposiciones de carácter internacional suscritas por el Estado y que son directamente aplicables y vinculantes en su ámbito jurisdiccional, nada nuevo aportan y, en consecuencia, son absolutamente prescindibles. ${ }^{20}$

Asimismo, también nos encontramos ante otro elenco de disposiciones normativas que se caracterizan por albergar, en primer término, una remisión en bloque a los derechos individuales y colectivos otorgados a la infancia y la adolescencia por la Constitución, los pactos y los acuerdos internacionales en materia de Derechos humanos ratificados por el Estado, muy especialmente la CDN. Acto seguido, y precisamente en este punto radica su originalidad, incorporan una referencia expresa a aquellos derechos que consideran merecedores de una especial atención y protección, que vienen a ser catalogados bajo la rúbrica de derechos específicos. Incluso, en determinadas ocasiones, como consecuencia de la extensión y amplitud que pueden llegar a adquirir los elementos integrantes de esta categoría legal, puede llegar a cuestionarse si la excepción no deviene, realmente, regla general y, en consecuencia, el criterio a seguir se invierte.

Finalmente, nos encontramos con un tercer modelo de referencia, cuya finalidad es la de desarrollar en un único texto normativo todo el conjunto de derechos básicos que otros instrumentos legales, de carácter estatal o internacional, ya han reconocido previamente a los niños, las niñas y los adolescentes. Efectivamente, no confiando, parece ser, en el conocimiento y buen uso de este acervo normativo ya preexistente, ciertos Estados emprenden la tarea de trasladar a su legislación nacional estas disposiciones. Añadir, que en no pocas ocasiones, la configuración y sistematización orgánica que se otorga a los preceptos que conforman este verdadero estatuto de la infancia y la adolescencia, no obedece a lógica o canon alguno de distribución

\footnotetext{
${ }^{19}$ Linacero, María, Protección jurídica del menor, Montecorvo, Madrid, 2001, p. 24.

${ }^{20}$ Hernández, Ana, "La convivencia de ámbitos normativos en la protección de la infancia: reflejo en la Comunidad Autónoma de Aragón”, Revista Aragonesa de Administración Pública, 2000, № 17, pp. 297-298.
} 
interna, y en caso de hacerlo, al guardar silencio al respecto, se imposibilita o dificulta el conocimiento de los verdaderos designios del legislador.

Tras apuntar estos tres grandes modelos, y reconociendo los pros y contras de cada uno de ellos, entendemos que el más adecuado, y por ende, por el que debiera decantarse el legislador chileno para dar cuerpo a la parte dispositiva del Proyecto de Ley de Protección Integral de la Niñez y la Adolescencia es el perfilado en último lugar. Ahora bien, para evitar los riesgos de su falta de coherencia interna, proponemos que una buena forma de sistematizar o acomodar su contenido sería la fijada por la reordenación de artículos de la CDN llevada a cabo por el propio Comité de los Derechos del Niño el año 1991, respecto a los informes iniciales, ${ }^{21}$ y 1996, respecto de los informes periódicos, que los Estados parte de la Convención deben presentar de acuerdo con lo estipulado en su artículo 44. ${ }^{22}$

Efectivamente, el Comité de los Derechos del Niño en un esfuerzo por dotar de lógica al contenido del texto de la Convención, y facilitar con ello la tarea de los Estados parte a la hora de rendir cuentas de sus actuaciones, dividió el articulado del tratado internacional en diversos subgrupos, que son los listados a continuación: medidas generales de aplicación; definición de niño/a; principios rectores (no discriminación, interés superior del niño/a, derecho a la vida, la supervivencia y el desarrollo, y respeto a la opinión del niño/a); derechos y libertades civiles; entorno familiar y otros tipos de tutela; salud básica y bienestar; educación, ocio y actividades culturales; $y$, finalmente, medidas especiales de protección. Pues bien, es precisamente este criterio de ordenación el que sugerimos sea utilizado por el Proyecto de Ley chileno. No únicamente por estar avalado por el órgano encargado de velar por el respeto de los principios y derechos dimanantes de la Convención, sino también por qué de este modo, además de facilitar el conocimiento y el entendimiento integral de los mandatos comprendidos en su articulado, los

${ }^{21}$ El propio Comité de los Derechos del Niño consciente de la necesidad de homogeneizar la estructura y el contenido de los distintos informes presentados por los Estados partes emitió en 1991 unas orientaciones generales respecto de la forma y contenido de los reportes iniciales. Este conjunto de directrices se configuró como punto de referencia constante para ayudar a los Estados a estructurar y a cumplir con las obligaciones asumidas en virtud del artículo 44 de la $\mathrm{CDN}$, agrupando los preceptos del mentado tratado internacional según su contenido y siguiendo una secuencia lógica. ComITÉ DE LOS DeREChos DEL Niño, "Orientaciones generales respecto de la forma y el contenido de los informes que han de presentar los Estados partes con arreglo al apartado a) del párrafo primero del artículo 44 de la Convención", 30 de octubre de 1991, Documento CRC/C/5.

${ }^{22}$ Comité de los Derechos del Niño, "Orientaciones generales respecto de la forma y el contenido de los informes que han de presentar los Estados partes con arreglo al apartado b) del párrafo primero del artículo 44 de la Convención”, 20 de noviembre de 1996, Documento CRC/C/58. 
subsiguientes informes - de seguimiento de la Convención- que el Estado chileno eleve al Comité ginebrino tendrán exactamente la misma estructura que su normativa nacional. ${ }^{23}$

\section{LA NIÑEZ Y LA ADOLESCENCIA COMO EJE VERTEBRADOR DEL SISTEMA}

Plantea dudas si la centralidad del nuevo marco normativo sobre niñez y adolescencia debe recaer en la familia -como así se manifiesta en los fundamentos del Proyecto de Ley- o si, por el contrario, más bien debiera estarlo en la propia infancia y la adolescencia, para de este modo evitar correr el riesgo de poner, una vez más, el énfasis en el mundo adulto. La Ley debe aspirar, más allá de ordenar legalmente la materia, a procurar la adecuación del sistema y los recursos a las necesidades de los niños, niñas y adolescentes, y no a la inversa como tradicionalmente ha venido acaeciendo. Este cambio de enfoque ha de permitirnos reducir el número de situaciones de posible maltrato institucional, así como dotar al nuevo modelo de cierta flexibilidad para poder atender de manera más adecuada las diferentes realidades que se le van presentando. De acuerdo con esta premisa, la nueva Ley debe apostar por un modelo innovador, dinámico y dúctil que le permita ir adaptándose a las necesidades emergentes y a las nuevas formas de atención que una sociedad en continua evolución reclama, respetando, en todo caso, la perspectiva de género $^{24}$ y el principio de la inclusión.

En este nuevo contexto, por supuesto, la familia debe jugar un rol esencial, pero desde una nueva representación, lejos del tan manido "con mis hijos/as no te metas", que aleja del foco de atención a sus verdaderos

\footnotetext{
${ }^{23}$ RavetLlat, Isaac, "Distintos modelos de recepción de los derechos de la infancia y la adolescencia por parte de las legislaciones autonómicas", La Ley - Derecho de Familia, 17 de noviembre de 2014, pp. 1-10.

${ }^{24}$ La perspectiva de género, ya prevista en el Convenio de las Naciones Unidas sobre la Eliminación de todo tipo de Discriminación hacia la Mujer, de 18 de diciembre de 1979, significa que todas las acciones, previsiones y garantías adoptadas por los poderes públicos y las instituciones privadas, tomen en consideración que las personas menores de edad pueden tener necesidades diversas atendiendo a la variable género y a los aspectos sexo-afectivos. De este modo, se deben tener en cuenta las especificidades propias del género de los niños, niñas y adolescentes en todo lo relativo al ejercicio de derechos (representación equilibrada en los órganos de participación, contenidos de las enseñanzas, acceso a la sanidad, entre otros) y en la percepción de las prestaciones por parte de los poderes públicos (por ejemplo, en la organización interna de los centros residenciales).
} 
protagonistas, las nuevas relaciones parentales deben fundamentarse y potenciar su rol de acompañamiento, promoción y educación en el ejercicio de los derechos y la asunción de responsabilidades por parte de niños, niñas y adolescentes.

Añadir a lo anterior, que la nueva normativa tampoco puede pasar por alto la necesidad de articular los mecanismos precisos para garantizar la legitimación activa de niños, niñas y adolescentes, recogiendo o reforzando la posibilidad de que la persona menor de edad pueda reclamar directamente la defensa de sus derechos ante las autoridades competentes, de acuerdo con lo preceptuado en el artículo 12 de la CDN y la Observación General $N^{\circ}$ 12 del Comité de los Derechos del Niño, de 20 de junio de 2009, relativa al derecho del niño/a a ser escuchado; además de prever su derecho de audiencia, a fin y efecto de respetar su toma en consideración en todos aquellos asuntos que sean de su incumbencia. ${ }^{25}$

Asimismo, y a efectos de distinguir las diferentes etapas y acepciones que se engloban dentro del término genérico de persona menor de edad, no solo tomando en consideración las diversas y cambiantes necesidades según el tramo etario en que se encuentra un individuo, sino también con el fin de adecuarlo al ideario y vocabulario empleado cada vez de manera más generalizada en nuestro ordenamiento jurídico, la nueva norma proyectada debiera distinguir con vehemencia entre las categorías de niño y niña, referida a las personas menores de catorce años de edad, y la de adolescente, propia de los sujetos mayores de catorce años y menores de dieciocho. ${ }^{26}$

Si bien es cierto que nuestra legislación nacional no se pronuncia expresamente acerca de la procedencia o no de la representación legal en materias que excedan del ámbito de la patria potestad, es decir, en cuestiones que vayan más allá de los aspectos patrimoniales que afectan

\footnotetext{
${ }^{25}$ En esta misma línea de interpretación no olvidar el Protocolo Facultativo de la Convención sobre los Derechos del Niño, relativo a un procedimiento de comunicaciones (AsAmblea General DE LAS NACIONES UNIDAS, A/RES/66/138, de 12 de diciembre de 2011) que en su artículo 5 reconoce legitimación activa para presentar comunicaciones individuales ante el Comité de los Derechos del Niño a toda persona o grupo de personas -sin discriminación alguna por razón de edad-sujetas a la jurisdicción de un Estado parte, que afirmen ser víctimas de una vulneración por parte del mismo Estado de una o varias disposiciones de la Convención y/o de sus Protocolos facultativos sustantivos.

${ }^{26}$ Para BARCiA, cit. (n. 2), p. 21, resulta fundamental la diferenciación entre las categorías de niño/a y adolescente definidas a partir del artículo 16 inciso $3^{\circ}$ de la Ley $\mathrm{N}^{\circ} .19 .968$, en virtud del cual se considera niño, niña a todo ser humano que no ha cumplido los catorce años, y adolescente a quien se encuentra entre los catorce y los dieciocho años de edad.
} 
a niños, niñas y adolescentes, ${ }^{27}$ tal circunstancia no puede traer consigo la aplicación automática a cualquier ámbito de la vida de los sujetos que aún no han alcanzado la mayoridad -por ejemplo en el contexto de los derechos extrapatrimoniales- de las categorías contenidas en el artículo 26 del Código Civil chileno -infante, púber, impúber, menor adulto-, pensadas e ideadas, más bien, tal y como ya avanzábamos en la parte inicial de nuestro trabajo, para un contexto exclusivamente patrimonial contractual.

En efecto, en el Derecho actual puede considerarse asentada la idea, según la cual, en el ámbito de los derechos de carácter extrapatrimonial -derechos de la personalidad- no rigen las reglas generales de capacidad aplicables al campo patrimonial, dado que el núcleo básico de estos es la libertad y la dignidad del individuo, y su ejercicio contribuye al libre desarrollo de la personalidad, por lo que en general, en este contexto se debiese permitir a todo sujeto tomar sus propias decisiones. ${ }^{28}$ Para el eficaz ejercicio de los derechos de la personalidad basta pues que el titular ostente capacidad natural, es decir, que el sujeto disponga de suficiente juicio en relación con el acto jurídico determinado que se pretende desarrollar. Esto, llevado al ámbito de los derechos de la infancia y la adolescencia, nos remite a las nociones de evolución de facultades y autonomía progresiva, sostenidos en los artículos 5 y 12 de la CDN.

Ahora bien, en cuanto a la fijación de la capacidad en materia extrapatrimonial, se ha entendido que la apreciación casuística es fundamental, lo que involucra la evaluación de una serie de factores o criterios aplicables a la situación particular de que se trate. Bajo nuestro punto de vista, en esta determinación uno de los factores clave es precisamente la edad de la persona, por tanto, no habría impedimento para que en algunos casos la ley establezca un rango etario - nosotros defendemos que los catorce años- a partir del cual se presuma la capacidad del niño, niña o adolescente para ejercer determinados actos. ${ }^{29}$

El desarrollo de esta idea nos parece sumamente útil para comprender el criterio de diferenciación etaria que proponemos para la Ley de Garantías y Protección Integral de los Derechos de la Niñez y la Adolescencia, toda

\footnotetext{
${ }^{27}$ Lathrop, cit. (n. 3), p. 943.

${ }^{28}$ SAntos, María José, "Menores y derechos de la personalidad. La autonomía del menor”, en: DíazMaroto, J.; Rodríguez, A. (Coords.), El menor ante el derecho en el siglo XXI, Anuario de la Facultad de Derecho, Universidad Autónoma de Madrid, Madrid, 2011, pp. 63-64.

${ }^{29}$ Santos, cit. (n. 28), p. 64.
} 
vez que tal pauta resulta coincidente con la forma en que otros cuerpos normativos han abordado la cuestión (Ley N 19.968, Ley $\mathrm{N}^{\circ} 20.418$, Ley $\mathrm{N}^{\circ} 21.030$, Ley $\mathrm{N}^{\circ} 21.120$ ). En efecto, como ya se ha descrito en el presente trabajo, esta es la situación imperante en algunas normas vigentes en la actualidad, donde los mayores de 14 años pueden otorgar autónomamente su consentimiento -salvo excepciones-, mientras que por debajo de esta edad se requiere la autorización del representante legal. La importancia de esta distinción recaería, además, en que, por regla general, pudiera presumirse -iuris tantum- que los adolescentes son plenamente capaces respecto del ejercicio de sus derechos extrapatrimoniales, salvo que la ley prevea lo contrario atendiendo a su interés superior, mientras que los niños y las niñas no lo son.

\section{AUTONOMÍA PROGRESIVA E INTERÉS SUPERIOR DEL NIÑO/A COMO PRINCIPIOS RECTORES DEL SISTEMA}

Tomando como referente los principios rectores de la CDN: la no discriminación (artículo 2); el interés superior del niño/a (artículo 3); el derecho a la vida, la supervivencia y el desarrollo (artículo 6); y la participación infantil y adolescente (artículo 12), entendemos que la Ley de Garantías y Protección Integral de los Derechos de la Niñez y la Adolescencia, si bien debe hacerse cargo de todos y cada uno de ellos, debe asegurarse, para marcar realmente un hito, que dos de los mentados principios (autonomía progresiva e interés superior del niño/a) reciben un trato adecuado. Consideramos que un enfoque apropiado de ambos ayudará a que la norma no se limite a enunciar reglas, a recoger derechos entelequia (declaraciones grandilocuentes pero vacías de contenido), sino que, por el contrario, sea capaz de dar un paso cualitativo hacia adelante.

\section{Autonomía progresiva}

A causa de su consideración como ciudadanos en potencia o en preparación, niños, niñas y adolescentes han estado históricamente marginados de los procesos de toma de decisiones, tanto en la esfera privada como en la esfera pública. ${ }^{30}$ Ciertamente, no será hasta la aprobación de la

${ }^{30}$ Ramírez, Mónica; Contreras, Sylvia, "Deconstruyendo la noción de infancia asociada a ciudadanía 
CDN que la persona menor de edad se estatuye como un ser en desarrollo pero sujeto de derechos, y no solo de derechos pasivos, es decir, a recibir prestaciones de los adultos, sino también de derechos activos como la libertad de conciencia, pensamiento y religión, la libertad de expresión e información, la libertad de asociación y reunión o el derecho a ser escuchado en todo aquello que le afecte de manera directa o indirecta. Se reconoce pues, al niño, niña o adolescente -al menos tendencialmente- como un semejante, y en consecuencia, como portador de los mismos derechos - libertades que el adulto. ${ }^{31}$ En otras palabras, cabe decir que la Convención pone fin al viejo axioma de contemplar a la niñez como los aún no -aún no adultos, aún no responsables, aún no capaces, aún no competentes, aún no fiables, aún no con los mismos derechos, aún no dignos de ser escuchados ${ }^{32}$ - contrapuesta a la categoría de los adultos representada por la idea de los ya si. ${ }^{33}$

Aceptar al niño, niña y adolescente como una persona y como un ciudadano no implica, en ningún caso, cuestionar ni poner en entredicho la autoridad de los adultos, sino reconocer el derecho de las personas menores de edad a estar presentes, a decir lo que piensan, en función de su edad y características evolutivas, ${ }^{34}$ en la toma de aquellas decisiones que les afecten y enfatizando, en todo caso, que el rol que tiene el adulto es el de llevar a cabo una misión de acompañamiento, promoción y educación. ${ }^{35}$ Una infancia y adolescencia protagonista implica necesariamente la participación activa de los niños, niñas y adolescentes en su entorno vital más cercano. En suma, la autonomía progresiva no debe leerse, y mucho menos interpretarse, como

y participación”, Revista Internacional de Investigación en Ciencias Sociales, 2014, Vol. 10, № 1, pp. 91-105.

${ }^{31}$ Gaitán, Lourdes, Sociología de la infancia, Editorial Síntesis, Madrid, 2006, p. 28. La Corte Interamericana de Derechos Humanos-CIDH, en adelante- en diversas sentencias también ha adoptado idéntico criterio: CIDH: Caso Atala Riffo y niñas vs. Chile. Fondo, Reparaciones y Costas. Sentencia de 24 de febrero de 2012. Serie C No. 239, párr. 197; CIDH: Caso Furlan y familiares vs. Argentina. Fondo, Reparaciones y Costas. Sentencia de 31 de agosto de 2012. Serie C No. 148, párr. 230; y CIDH: Caso Mendoza y otros vs. Argentina. Fondo, Reparaciones y Costas. Sentencia de 14 de mayo de 2013. Serie C No. 260, párr. 143.

32 Archard, David, Children Rights and Childhood, Routledge, London, 1993, p. 30.

${ }^{33}$ Verhellen, Eugeen, Convention on the Rights of the Child, Garant Publishers, Gent, 1997, p. 16; CASAs, Ferran, Infancia: perspectivas psicosociales, Paidós, Barcelona, 1998, p. 33.

${ }^{34}$ O'Callaghan, Xavier, Libertad de expresión y sus límites: honor, intimidad e imagen, Revista de Derecho Privado, Madrid, 1991, pp. 165-166.

${ }^{35}$ Bercovitz, Rodrigo, "Comentarios a los artículos 154 y ss. del Código Civil", en Bercovitz, R. (Coord.), Comentarios a las reformas del Derecho de Familia, Tecnos, Madrid, 1984, Vol. 2, p. 1047. 
si de una arma arrojadiza se tratare frente al deber-derecho preferente de los progenitores de educar a sus hijos e hijas. Tal concepción, estimamos, es parcial, tendenciosa y, si nos apuran, incluso mal intencionada.

De este modo, escuchar e incluir su voz no representa apoyar acríticamente sus opiniones o sus decisiones, sino entablar un diálogo respetuoso en el que los niños, niñas y adolescentes se integren como sujetos activos en sus comunidades. ${ }^{36}$ Así, la CDN -artículos 5 y $12-$ hace referencia a la participación no como una finalidad en sí misma, sino como un procedimiento que debe garantizar la capacidad de los niños, niñas y adolescentes de tomar decisiones y de ser tomados en consideración en aquellos temas que les afecten. La Convención ofrece, por tanto, un panorama en el que la persona menor de edad es un individuo, además de miembro de una familia y de una comunidad, con derechos y responsabilidades adaptados a sus distintas etapas de desarrollo. Al aceptar los derechos de los niños, niñas y adolescentes desde esta perspectiva, la Convención orienta firmemente sus mandatos hacia el pleno reconocimiento de la personalidad integral del niño, la niña y el adolescente. ${ }^{37}$

Arribados a este punto, consideramos particularmente interesante que el Proyecto de Ley de Garantías y Protección Integral de los Derechos de la Niñez y la Adolescencia, se sume a la tendencia seguida a nivel internacional, iniciada ya por la CDN (artículo 5), de vincular el derecho del niño, niña y adolescente a ser escuchado, así como el alcance que han de tener sus opiniones, a la edad - elemento cronológico objetivo-y madurez -concepto jurídico indeterminado- del individuo. ${ }^{38}$

Se trata ésta de una técnica, que si bien parte de las tesis de la madurez, no renuncia a la oportunidad de prever, para actos de especial trascendencia -tanto personal como patrimonial-, ciertos límites objetivos expresamente predefinidos por la norma, fundamentados en el simple hecho de haber o no alcanzado una edad previamente estipulada. En otras palabras, tan solo se reconoce, o mejor dicho se presume, la capacidad natural a partir de un específico momento cronológico, que oscilará en atención a la naturaleza de los hechos ante los que nos encontremos.

A resultas de esta alternativa, la redacción de los preceptos relativos

\footnotetext{
${ }^{36}$ Comité de los Derechos Del NiÑo, “Observación General N ${ }^{\circ} 12$, relativa al derecho del niño a ser escuchado", 20 de julio de 2009, Documento CRC/C/CG/12.

37 Verhellen, cit. (n. 33), pp. 80-81, CASAs, cit. (n. 33), p. 219.

${ }^{38}$ GIL, Ana María, ¿Privacidad del menor en internet?, Thomson Aranzadi, Cizur Menor, 2015, p. 92.
} 
a la autonomía progresiva de los niños, niñas y adolescentes debieran abandonar definitivamente -al igual que hiciere la $\mathrm{CDN}$ - la práctica tradicional de vincular la adquisición -gradual- de la capacidad de ejercicio -de obrar-, única y exclusivamente atendiendo al dato objetivo de ostentar una determinada edad. Así, al exigirse que junto con el elemento cronológico también se tome en consideración la madurez de la persona, se da por sentado que un simple indicador etario no puede predeterminar la trascendencia, validez y efectos de los actos jurídicos por ella acometidos. Los niveles de comprensión de los niños, niñas y adolescentes no siempre van ligados de manera uniforme a su edad biológica. Por ende, la información, el nivel educativo, la experiencia, el entorno, las expectativas sociales, culturales y el grado de apoyo, entre otros, contribuyen, más allá del mero dato característico de haber cumplido un determinado número de años, a la mayor o menor capacitación del individuo para formarse un juicio razonable e independiente.

Por consiguiente, el Proyecto de Ley en comento, así como las disposiciones que a posteriori tendrán que adaptarse a sus preceptos, debieran apostar por un modelo que podríamos calificar de mixto o ecléctico que busca facilitar al máximo el punto de encuentro o el equilibrio perfecto entre seguridad y realidad, evitando el doble escollo que supone, de una parte, la brusquedad en el paso un ictu a la capacidad y, de otra, el excesivo casuismo con el que corremos el riesgo de toparnos, para lograr así que el beneficio de la persona menor de edad y su preparación para la vida sean el norte que guíe el devenir de las instituciones a él referidas. ${ }^{39}$

Significado lo anterior, apuntar que ante ese nuevo escenario la cuestión se circunscribe en concretar qué se entiende por ostentar madurez suficiente, pues nos encontramos ante un concepto jurídico indeterminado en torno al cual no existe una definición legal unificada. Cada niño y niña es diferente, y por ende es muy difícil establecer cuándo ostenta o no la capacidad de ejercicio necesaria, debido a su desarrollo intelectual, para poder ser dueño de su propia persona. ${ }^{40}$

Por nuestra parte, consideramos que una persona menor de edad

\footnotetext{
${ }^{39}$ LoRente, María Cristina, Los derechos al honor, a la intimidad personal y familiar y a la propia imagen del menor, Thomson Aranzadi, Cizur Menor, 2015, p. 92; LAMA, Alejandra, La protección de los derechos de la personalidad del menor de edad, Tirant lo Blanch, Valencia, 2006, pp. 45-56. También es de la misma opinión Moreno, Ángela, Intimidad y menores, Centro de Estudios Políticos y Constitucionales, Madrid, 2017, p. 140.

${ }^{40}$ Moreno, cit. (n. 39), p. 137.
} 
detenta la madurez suficiente o el autogobierno - capacidad natural- cuando demuestra tener la suficiente aptitud psíquica para la válida y efectiva prestación del consentimiento requerido para el ejercicio de un derecho $-\mathrm{O}$ para la manifestación de una opinión-, así como para asumir las consecuencias que para el desarrollo de su libertad futura tenga esa disposición de voluntad. En suma, el individuo además de congregar las facultades necesarias para emitir conscientemente una declaración de voluntad, debe asimismo conocer cuáles son los efectos jurídicos derivados de la misma. ${ }^{41}$

\section{Interés superior del niño/a}

El principio del interés superior del niño/a es un principio clave para poder comprender el alcance del cambio de paradigma que supuso la aprobación de la CDN en 1989.42 Esa determinación en el interés del niño, niña o adolescente, la búsqueda del mismo, deben servir de guía y estar presentes, como señala el art. 3 de dicha Convención, en todas las medidas que tomen con respecto a las personas menores de edad las instituciones públicas o privadas de bienestar social, los tribunales, las autoridades administrativas o los órganos legislativos. ${ }^{43}$

El principio del interés superior del niño/a pone acertadamente el acento en su realidad como sujeto digno de atención, promoción, provisión y protección. Este criterio ha de aplicarse en todas aquellas situaciones o conflictos donde se hallen involucradas las personas menores de edad. Pero esta cláusula general, lejos de configurarse como un concepto pacífico, ha sido y es objeto de múltiples y diversas controversias que tienen una influencia negativa en su eficacia práctica. ${ }^{44}$

${ }^{41}$ Díaz de Valdés, José Manuel, "Un marco constitucional para los tratamientos médicos de niños, niñas y adolescentes", Revista Chilena de Derecho, 2010, º 2, p. 276.

${ }^{42}$ Aguilar, Gonzalo, "El principio del interés superior del niño y la Corte Interamericana de Derechos Humanos", Estudios Constitucionales, 2008, № 1, p. 229.

${ }^{43}$ En un intento de dar respuesta a los múltiples interrogantes que surgen a la hora de dar contenido al concepto jurídico indeterminado del interés superior del niño/a, el Comité DE LOS DERECHOS DEL NiÑo, "Observación General $N^{\circ}$. 14, sobre el derecho del niño a que su interés superior sea una consideración primordial", 29 de mayo de 2013, Documento CRC/C/GC/14, efectúa un comentario exhaustivo del citado principio rector contenido en el párrafo primero del artículo 3 de la Convención sobre los Derechos del Niño.

${ }^{44}$ Ravetllat, Isaac; Pinochet, Ruperto, "El interés superior del niño en el marco de la Convención Internacional sobre los Derechos del Niño y su configuración en el Derecho Civil chileno", Revista Chilena de Derecho, 2015, Vol. 42, N.3, pp. 904-906; y Santamaría, María Luisa, El concepto del interés superior del niño y su dimensión constitucional, Universidad Politécnica de Valencia, Valencia, 
Así, cuando tratamos de determinar cómo y quién decide cuál es y cómo se concreta este interés nos enfrentamos a una primera divergencia. Las personas que abordan y deciden esa cuestión, por regla general representantes legales, autoridades administrativas y jueces, no operan de manera aséptica y neutral, sino que, por el contrario, en la mayoría de las ocasiones, aún actuando con la mejor intención, no logran sustraerse a sus propias convicciones y prejuicios y, consciente o inconscientemente, encaran la cuestión y valoran ese interés desde su propia óptica vital e ideología, en lugar de hacerlo pensando única y exclusivamente en el niño o la niña, con sus necesidades, sentimientos y escala de valores distintos de los que, tal vez, presentan los adultos.

Estamos pues, ante una noción de difícil concreción frente a la que deben redoblarse los esfuerzos para delimitar si realmente se está aplicando por parte de los actores sociales que rodean la vida del niño/a y cómo se está procediendo a ello (e interpretando), para, de esta forma, evitar que tal locución se convierta en lo que algunos autores definieron como una noción mágica, evanescente, que pueda dar lugar a la arbitrariedad jurídica y al abuso de derecho. ${ }^{45}$

Esta complejidad conceptual ayuda a explicar el por qué, a pesar de la fuerte atracción instintiva que tiene este principio en el establecimiento de los derechos de la niñez y la adolescencia, han sido muchos los autores que han expresado reservas hacia el mismo, llegando incluso a ser calificado como un Caballo de Troya que introduce consideraciones culturales en el terreno de los derechos del niño y de la niña que pueden minar el consenso reflejado en esta materia. ${ }^{46}$

En este sentido, y para evitar los riesgos de caer en una lectura excesivamente ambigua de esta cláusula abstracta, entendemos que la Ley de Garantías y Protección Integral de los Derechos de la Niñez y la Adolescencia debería acercarse al sistema de concreción adoptado por los países anglosajones para dar contenido al principio del interés superior del

\footnotetext{
2017, pp. 1-3.

${ }^{45}$ Carbonnier, Jean, “Comment S. Cour d'Appel Paris, 10 de abril de 1959”, Dalloz, 1969, №. 1, 1960, p. 24.

${ }^{46}$ Una crítica a la generalidad, vaguedad e imprecisión con la que aparece formulado el término en el artículo 3 de la Convención sobre los Derechos del Niño la encontramos en DogliotTi, Massimo, "Che cosa é l'interesse del minore?", Il Diritto di Famiglia e delle Persone, 1992, № 4, p. 306, Buirette, Patricia, "Réflexions sur la Convention Internationale des Droits de l'Enfant", Revue Belge de Droit International, 1990, $\mathrm{N}^{\circ}$ 1, p. 73, y PiconTó, Teresa, La protección de la infancia. Aspectos sociales y jurídicos, Egido, Zaragoza, 1996, pp. 91-93.
} 
niño/a. ${ }^{47}$ Este criterio no es otro que el de incorporar junto con enunciados legales del tipo cláusula general, un elenco de criterios indicativos que pretenden especificar y facilitar la búsqueda del interés de la persona menor de edad, criterios que vendrían a reflejar lo que la sociedad considera en cada momento como los factores más importantes o relevantes a la hora de definir lo que significa el interés de los niños, las niñas y los adolescentes.

\section{CLÁUSULA DE DIFUSIÓN}

Siguiendo el modelo establecido por el artículo 42 de la CDN, y teniendo en cuenta las observaciones efectuadas por el Comité de los Derechos del Niño en el último informe presentado por el Estado chileno (2015), ${ }^{48}$ en el que se apuntaba la necesidad de que el Estado reafirmase sus esfuerzos para difundir y promover sistemáticamente la CDN entre el público en general, y entre los profesionales que trabajan con y para la infancia y la adolescencia, los medios de comunicación, los progenitores y los propios niños, niñas y adolescentes, en particular, la Ley proyectada debería prever una cláusula de difusión, a fin de garantizar el cumplimiento de este requerimiento efectuado por el Comité ginebrino.

Además, se debería velar para que los principios y disposiciones de la CDN se incorporen de manera progresiva a los diferentes planes de estudio de todos los niveles y de todos los centros educativos. Así como en los itinerarios curriculares de las diferentes carreras universitarias en que los futuros profesionales del ámbito social se estén formando. Idéntica medida se debería garantizar en los temarios y programas de las oposiciones públicas convocadas por los órganos de la administración del Estado.

\section{CORRESPONSABILIDAD DE LOS PODERES PÚBLICOS}

Hay que superar de manera definitiva cualquier tipo de dificultad a

\footnotetext{
${ }^{47}$ Estrada, Francisco, "Principios del procedimiento de aplicación de medidas de protección de derechos de niños y niñas", Revista de Derecho Escuela de Postgrado Universidad de Chile, 2015, $\mathrm{N}^{\circ} .8$, p. 162.

48 Comité de los Derechos del Niño, "Observaciones finales. Examen de los informes periódicos cuarto y quinto presentados por el Estado Chileno", 30 de octubre de 2015, Documento CRC/C/CHL/ $\mathrm{CO} / 4-5$, párr. 94.
} 
la hora de interpretar las diferentes competencias o atribuciones locales, regionales y estatales, con incidencia directa en la atención a la infancia y la adolescencia. Deben quedar establecidos de manera clara y detallada los circuitos de atención y protección, así como los sistemas de coordinación entre los diferentes servicios y recursos, evitando de esta forma que la asunción de responsabilidades y el ejercicio de la autoridad se diluya entre los diferentes estamentos.

Por lo tanto, estimamos que la Ley debiera marcar con claridad las bases organizadoras del sistema, los circuitos esenciales de intervención, sin perjuicio, por supuesto, de otros desarrollos normativos. Deben evitarse duplicidades y disfunciones y generarse un marco de actuación adecuado para proporcionar una atención de calidad a las familias y a los niños, niñas y adolescentes, así como una gestión de los recursos eficaz, eficiente y tan próxima al ciudadano como sea posible.

En definitiva, los servicios sociales de ámbito estatal implementados en el territorio deberían convertirse en la herramienta adecuada para llevar a cabo las tareas de promoción, prevención y detección de las situaciones de riesgo o de exclusión social en el seno de la propia comunidad, mediante la utilización de los recursos sociales disponibles. En este contexto, hay que reforzar la obligación sobre la prevención del riesgo a cargo de las oficinas locales de la niñez, y crear o mejorar los protocolos de actuación por parte de los profesionales de los servicios sociales de atención primaria. Estos servicios sociales mantendrían también la función de derivación al equipo especializado de protección a la infancia, el que debería ostentar las competencias de diagnóstico y proposición y seguimiento técnico de las medidas protectoras del niño, la niña o el adolescente.

\section{SISTEMA PÚBLICO DE PROTECCIÓN A LA INFANCIA Y LA ADOLESCENCIA}

Este último punto queremos dedicarlo a esbozar cuáles serían, a nuestro juicio, los principales lineamientos del sistema público de protección a la niñez y la adolescencia por el que debería apostar el legislador chileno en el Proyecto de Ley de Garantías. Ciertamente, y para tratar de superar las críticas esgrimidas frente al vigente modelo judicializado de protección a las personas menores de edad, se advierte una incipiente tendencia doctrinal, a la cual nos adscribimos, proclive a avanzar hacia un régimen que podría calificarse 
como de mixto o intermedio, pues combina dos niveles diferenciados de intervención: uno de carácter administrativo, ubicado en sede local, y otro de naturaleza judicial, atribuido a los Tribunales de Familia. ${ }^{49}$

Este proceso de desjudicialización -o administrativización, si se prefiere- de los escalones primarios del sistema público de protección a la niñez y la adolescencia, y por ende la consecuente potenciación del papel de las administraciones locales a través de sus servicios sociales, parece, a priori, y siempre que tales entidades de base local cuenten con los recursos económicos y personales suficientes, revelarse como la solución más ágil y eficaz para revitalizar el más que cuestionado actual modelo SENAME de protección a la infancia y la adolescencia. Esta opción nos llevaría a evitar la necesidad de tener que acudir, en todo caso, a un procedimiento judicial excesivamente lento y burocratizado y que se revela como claramente inoperativo en las situaciones no conflictivas que precisamente por no serlo enervan o hacen innecesaria la presencia de la citada autoridad.

Efectivamente, si bien la Ley $N^{\circ} 19.968$, de Tribunales de Familia, señala expresamente que la competencia de dichos órganos judiciales se extiende tan solo a hechos de grave vulneración de derechos, en la praxis, son múltiples los casos que podrían calificarse de una entidad inferior a aquélla, que son, sin embargo, puestos en conocimiento de la judicatura para la resolución de los mismos, tales como: deserción escolar, falta de cupos en establecimientos escolares, descoordinaciones en la entrega de servicios de las entidades de la red de salud o de organismos que otorgan beneficios sociales, entre otros. Por ello, cobra particular importancia la recomendación emitida por el Comité de Derechos del Niño de Naciones Unidas en relación con que el Estado de Chile desjudicialice el actual sistema de protección, a través de la creación de un servicio de protección administrativo especializado y dotado de recursos suficientes, reservando la intervención de la instancia judicial únicamente para casos graves. ${ }^{50}$

\footnotetext{
${ }^{49}$ Retamal, Alejandra, "Atención de la infancia vulnerable en Chile: diagnóstico sobre su institucionalidad y propuestas de mejoras", en: Retamal, A. (Ed.), Cuadernos de Trabajo del Centro UC de la Familia, $\mathrm{N}^{\circ}$ 1, P. Universidad Católica de Chile, Santiago, 2017, p. 52; Lathrop, Fabiola, "La protección especial de derechos de niños, niñas y adolescentes en el Derecho chileno", Revista Chilena de Derecho Privado, 2014, $\mathrm{N}^{\circ} 22$, pp. 207-208. En este punto también resultan interesantes las reflexiones de CARRETTA, Francesco, "La desformalización del proceso judicial de familia e infancia", Revista de Derecho P. Universidad Católica de Valparaíso, 2014, $\mathrm{N}^{\circ} 42$, pp. 481-495, quien se cuestiona acerca de la verdadera naturaleza jurídica de la denominada desformalización del proceso judicial de familia e infancia tras la entrada en vigencia de la Ley $\mathrm{N}^{\circ}$. 19.968.

${ }^{50}$ El Estado chileno, tal y como se encargó de recordarnos el propio Comité de los Derechos del Niño
} 
A tenor de lo apuntado, un sistema mixto de protección parece sugerir que las situaciones de riesgo, amenaza o vulneración no grave de derechos, queden atribuidas a la autoridad administrativa (en el caso de la normativa proyectada en Chile, a las Oficinas Locales de Niñez, en adelante OLN), ${ }^{51}$ entidades públicas comunales competentes para acordar o declarar, a través de un procedimiento administrativo, si se da o no la mentada situación fáctica; así como, en su caso, dictaminar una o diversas medidas de protección de carácter administrativo, encaminadas a disminuir o hacer cesar dicha contingencia. Este tipo de medidas, en ningún caso pueden significar la separación del niño/a o adolescente de su núcleo o contexto familiar, por el contrario, tal facultad debe quedar siempre reservada a la autoridad judicial.

En consecuencia, las OLN -que deben ser creadas por el Ministerio de Desarrollo Social y Familia- están llamadas a convertirse en el epicentro del sistema de protección pública administrativa de los niños, niñas y adolescentes. Estos órganos locales con competencias en una comuna o agrupación de ellas, a lo largo de todo el territorio nacional, deben erigirse en los encargados de la protección administrativa tanto general -o universalcomo especializada de los derechos de la niñez y la adolescencia. ${ }^{52} \mathrm{Su}$ coordinación y supervisión corresponderá al Ministerio de Desarrollo Social y Familia, a través de la Subsecretaría de la Niñez. ${ }^{53}$

en sus recomendaciones finales tras el examen de los informes periódicos cuarto y quinto, de octubre de 2015, está claramente al debe en esta cuestión. En este sentido el Comité ginebrino expresa su preocupación por la falta de una ley de protección integral de todos los niños y niñas. Así como lamenta que no hayan tenido éxito los intentos realizados en 2005 y 2012 para cambiar tal situación. COMITÉ DE Los Derechos Del Niño, "Observaciones finales. Examen de los informes periódicos cuarto y quinto presentados por el Estado Chileno", 30 de octubre de 2015, Documento CRC/C/CHL/CO/4-5, párr. 8-9.

${ }^{51}$ Las Oficinas Locales de Niñez vienen a superar a las Oficinas de Protección de Derechos - OPDs -, que si bien en teoría debían facilitar e impulsar el desarrollo institucional de sistemas locales de protección de la infancia y la adolescencia, en un territorio determinado, en la práctica, debido a la alta demanda de trabajo a estas oficinas, no han podido desarrollar todas las líneas de intervención que le fueron encomendadas por la Ley $\mathrm{N}^{\circ}$. 20.032, en especial la línea preventiva. Por ello, nos parece de suma importancia que las funciones de las nuevas OLN sean reformuladas para conseguir que desplieguen una función preventiva con las familias e inicien también campañas a nivel local de promoción y sensibilización a nivel acerca del respeto y desarrollo de los derechos de la niñez y la adolescencia, así como de sus capacidades.

${ }^{52}$ El proyecto de Ley de Garantías y Protección Integral de los Derechos de la Niñez y la Adolescencia atribuye a las OLN tanto la denominada como protección administrativa general - o universal -, pensada con respecto de todo niño, niña o adolescente con el fin de promover sus derechos y prevenir riesgos de vulneración, como la conocida como protección administrativa especializada, destinada ya a dar respuesta a situaciones de amenaza de derechos que un niño, niña o adolescente, o grupo de ellos, pueda estar viviendo.

${ }^{53}$ Las OLN contarán con un coordinador local y un equipo multidisciplinario con gestores de casos, 
Aun estando de acuerdo con lo anterior, uno de los grandes debates todavía por resolver es el atingente al ámbito de extensión de las susodichas competencias atribuidas a las OLN. Desde nuestro punto de vista, restringir o limitar su ámbito de actuación a tan solo los casos de amenaza leve, iría en detrimento de la tan anunciada descongestión y desjudicialización del sistema de protección público a la infancia y la adolescencia, con el consiguiente peligro de que esa consigna se convierta más en un eslogan publicitario, en una mera declaración de intenciones, que no en un verdadero cambio de paradigma. Por el contrario, nuestra apuesta pasa por extender la competencia de las OLN a las situaciones de vulneración no graves de derechos. Es decir, que este órgano administrativo sea el encargado de declarar, no únicamente las situaciones de riesgo -amenaza de derechos-, sino también los supuestos de vulneración no graves de derechos, así como, caso de ser preciso, acordar la puesta en marcha de las actuaciones pertinentes -medidas de protección administrativa especializada- para reducirlas o ponerles fin. También debiera corresponderle llevar a cabo el seguimiento de la evolución de la persona menor de edad en la familia. Es más, dado que el Proyecto de Ley estatuye los principios generales de actuación de las administraciones públicas frente a situaciones de desprotección social, debe incluirse la obligación de las OLN de investigar los hechos que conozca para corregir tales situaciones. ${ }^{54}$

Además, y vinculado con lo esgrimido ut supra, el Proyecto de Ley no puede circunscribirse, sin más, a entregar a un futuro reglamento la regulación del procedimiento administrativo que deba proseguirse para declarar la situación de desprotección de un niño, niña o adolescente y acordar la correspondiente medida de protección administrativa, por el contrario, en consideración a la naturaleza restrictiva de derechos de la persona menor de edad y demás personas de su entorno que puede revestir la medida de protección, la ley es la que debiera ocuparse directamente de su tratamiento.

De igual modo, entendemos como fundamental que frente a las resoluciones que emitan las OLN sea posible una impugnación -u oposiciónante la autoridad judicial competente en materia de familia. La idea es que

\footnotetext{
y su personal contará con una doble adscripción: administrativamente dependerá de la entidad local competente, mientras que funcionalmente lo hará de la Subsecretaría de la Niñez.

${ }^{54}$ En la actualidad, desde el año 2019, hay 12 pilotos de las nuevas Oficinas Locales de la Niñez, repartidas en nueve Regiones del país. A la fecha de cierre de este artículo - diciembre de 2020 - aún no se cuenta con una evaluación oficial del proceso de implementación de las mentadas dependencias locales para poder abordar con conocimiento de causa las luces y sombras de su puesta en funcionamiento.
} 
la intervención administrativa brinde una protección inmediata al niño, niña y adolescente, pero ello sin detrimento a que las personas afectadas progenitores, personas que ostenten el cuidado de la persona menor de edad o el propio niño, niño o adolescente- ostenten la posibilidad de instar $a$ posteriori un control judicial del acto administrativo adoptado por la OLN. Esta posibilidad de impugnación judicial debiera quedar configurada en un doble sentido: objetar la declaración administrativa que considera que el niño, niña o adolescente se encuentra, efectivamente, en una situación de amenaza o de vulneración no grave de sus derechos; $y / o$ oponerse a la medida protectora acordada por la autoridad pública administrativa. Por último, apuntar que en esta impugnación judicial debe darse una inversión de la carga de la prueba. Es decir, deben ser los progenitores o personas al cuidado del niño, niña o adolescente los que tengan que acreditar la no existencia de razones suficientes que justifiquen la necesidad de adoptar una medida de protección administrativa, así como de no estar conformes con la medida en concreto que se haya dictaminado.

Por lo que a las situaciones de vulneración grave de derechos y garantías se refiere, en estos casos, ahora sí, debe ser la autoridad judicial competente -Tribunales de Familia- la encargada de dictaminar las medidas de protección correspondientes, que supondrán, en principio, la separación del niño, niña o adolescente de su contexto familiar. En este sentido, y con la intención de facilitar y orientar la tarea de los operadores sociales encargados de delimitar si una concreta situación de hecho supone una vulneración grave de derechos de un niño, niña o adolescente, consideramos de sumo interés que la norma, junto con ofrecer un concepto -genérico- acerca de qué debe entenderse por vulneración grave, liste, acto seguido, a título meramente ejemplificativo -numerus apertus- las principales situaciones que queden circunscritas dentro de este tipo de vulneración.

Así, entendemos por situación de vulneración grave de derechos, aquella que afecta al desarrollo y bienestar del niño, niña o adolescente, limitándolo o perjudicándolo gravemente, por cualquier circunstancia personal, familiar o social, siempre que para protegerlo de forma efectiva y garantizar sus derechos fundamentales, sea aconsejable o imprescindible separarlo de su núcleo familiar. En consecuencia, al igual que sucede al referirnos a las situaciones de amenaza, riesgo o vulneración no grave, en estos casos también nos encontramos ante una situación fáctica-de hecho-, una condición de la vida real de la persona en la que se haya su entorno familiar y social, y que afecta de manera grave el bienestar o la calidad 
de vida del niño, niña o adolescente. En realidad, la verdadera diferencia entre situación de amenaza, riesgo o vulneración no grave de derechos y la situación de vulneración grave de los mismos se circunscribe a una cuestión de intensidad. Intensidad en la afectación del desarrollo y bienestar del niño, niña o adolescente (perjuicio o limitación en el primero, y falta o perjuicio o limitación grave en el segundo), e intensidad en la necesidad de adoptar medidas protectoras más drásticas (separación o no) para asegurar ese bienestar o calidad de vida básicas.

Un papel trascendental en esta cuestión es el llamado a ejercer por el Servicio Nacional de Protección Especializada de la Niñez y la Adolescencia, organismo éste que verá la luz en un futuro muy cercano, de hecho a fines de octubre de 2020 el legislativo dejó en condiciones de convertirse en Ley de la República la norma que crea su existencia. Esta nueva institucionalidad, dependiente del Ministerio de Desarrollo Social y ya no del Ministerio de Justicia y Derechos Humanos, establecerá las líneas programáticas para generar mecanismos o servicios de protección a los niños, niñas y adolescentes. Además se encargará de crear convenios con los organismos colaboradores, acreditando dichas organizaciones de la sociedad civil. La iniciativa también genera la figura de un director general y un consejo de expertos que debe trabajar marcando las directrices de actuación.

\section{CONCLUSIONES}

El carácter programático y voluntarista de no pocos de los preceptos contenidos en la parte dispositiva del Proyecto de Ley de Garantías y Protección Integral de los Derechos de la Niñez y la Adolescencia parece conciliarse mal con las exigencias de una correcta técnica legislativa. Tal limitación tan solo podría quedar contrarrestada por unas consistentes y atrevidas Disposiciones finales, que vinieran a adaptar el resto del ordenamiento jurídico a la nueva realidad normativa anunciada por el mentado Proyecto de Ley. En caso contrario se corre el riesgo que dicha norma se cierre en sí misma y se convierta en su peor enemiga.

En el presente estudio constatamos que la acción legislativa del Estado chileno, transcurridos treinta y un años desde la ratificación de la CDN, sigue caracterizándose por responder a una superposición progresiva de estratos normativos con derogación o desplazamiento parcial de los asentados previamente. Tal circunstancia evidencia, la suma urgencia, más aún tras 
el despacho por la Cámara de Diputados del Proyecto de Ley que crea el Servicio Nacional de Protección Especializada a la Niñez y Adolescencia, de contar en Chile, de una vez por todas, con un instrumento legal que reúna tanto la regulación destinada a todos los niños, niñas y adolescentes en general, como la relativa a sentar las bases del nuevo sistema -mixtode protección pública de las personas menores de edad que se encuentren en situación de particular vulnerabilidad o hayan sido vulnerados en sus derechos.

Asimismo, también subrayamos la necesidad de resaltar el papel fundamental llamado a jugar por la familia dentro del Proyecto de Ley de Garantías, ahora bien desde una nueva representación de la mentada institución, lejos del tan manido con mis hijos e hijas no te metas, que aleja el foco de atención a sus verdaderos protagonistas. Así, las nuevas relaciones parentales deben fundamentarse y potenciar su rol de acompañamiento, promoción y educación en el ejercicio de los derechos y la asunción de responsabilidades por parte de niños, niñas y adolescentes.

Finalmente, defendemos la incorporación en el Proyecto de Ley de Garantías de una cláusula general en virtud de la cual, y en aras a superar el elemento objetivo cronológico como único criterio a tomar en consideración a la hora de determinar si una persona menor de edad ostenta suficiente nivel de capacidad para ejercer por sí determinados derechos, se presuma-iuris tantum-que los y las adolescentes -14 años de edad-son plenamente capaces con respecto al ejercicio autónomo de sus derechos de la personalidad, salvo que la ley prevea lo contrario atendiendo a su interés superior, mientras que a los niños y niñas - hasta los catorce años-, en cambio, no les favorece dicha presunción.

En definitiva, la nueva normativa de infancia y adolescencia debe aprovechar la ocasión para huir de las generalizaciones, las ambigüedades y las declaraciones grandilocuentes, e intentar dar un paso al frente. Una política legislativa seria y eficaz, llamada a dotar de cierta homogeneidad y consistencia a este ámbito del ordenamiento jurídico, no se alcanza con la aprobación de una o diversas disposiciones de nuevo cuño plagadas de principios muy loables pero frecuentemente superfluos e innecesarios. Por el contrario, consideramos que la única forma válida y eficaz de lograr este objetivo es procurando una regulación metódica y coherente que venga a normalizar el galimatías normativo existente en el Derecho chileno en torno a la realidad de los niños, niñas y adolescentes que se encuentran bajo su jurisdicción. 


\section{BIBLIOGRAFÍA CITADA}

Aguilar, Gonzalo, "El principio del interés superior del niño y la Corte Interamericana de Derechos Humanos", Estudios Constitucionales, 2008, N 1, p. 223-247.

ArChard, David, Children Rights and Childhood, Routledge, London, 1993.

BARCIA, Rodrigo, "Derechos fundamentales y autonomía progresiva de la infancia”, en: Lepin, C.; Gómez de la Torre, M. (Coords.), Estudios de Derecho Familiar I, Thomson Reuters, Santiago, 2016, pp. 211-220.

BARCIA, Rodrigo, "La capacidad extrapatrimonial de los niños y adolescentes conforme a sus condiciones de madurez", Ius et Praxis, 2013, Vol. 19, $\mathrm{N}^{\circ} 2$, pp. 3-57.

Bercovitz, Rodrigo, "Comentarios a los artículos 154 y ss. del Código Civil", en Bercovitz, R. (Coord.), Comentarios a las reformas del Derecho de Familia, Tecnos, Madrid, 1984, Vol. 2, pp. 1042-1048.

Buirette, Patricia, "Réflexions sur la Convention Internationale des Droits de l'Enfant', Revue Belge de Droit International, 1990, N 1, pp. 1085-1087.

Carbonnier, Jean, "Comment S. Cour d'Appel Paris, 10 de abril de 1959", Dalloz, 1969, N 1, pp. 650-673.

Carretta, Francesco, "La desformalización del proceso judicial de familia e infancia", Revista de Derecho P. Universidad Católica de Valparaíso, 2014, № 42, pp. 481-495. 1998.

CASAS, Ferran, Infancia: perspectivas psicosociales, Paidós, Barcelona,

Comité de los Derechos del Niño, "Observaciones finales. Examen de los informes periódicos cuarto y quinto presentados por el Estado Chileno", 30 de octubre de 2015, Documento CRC/C/CHL/CO/4-5.

Comité de los Derechos del Niño, "Observación General N. 14, sobre el derecho del niño a que su interés superior sea una consideración primordial”, 29 de mayo de 2013, Documento CRC/C/GC/14.

Comité de los Derechos del Niño, "Observación General No. 12, relativa al derecho del niño a ser escuchado", 20 de julio de 2009, Documento CRC/C/CG/12.

Comité de los Derechos del Niño, "Observación General No. 5, Medidas generales de aplicación de la Convención sobre los Derechos del Niño", 27 de noviembre de 2003, Documento CRC/GC/2003/5.

Comité de los Derechos del Niño, "Orientaciones generales respecto de la forma y el contenido de los informes que han de presentar los Estados partes con arreglo al apartado b) del párrafo primero del artículo 44 de la Convención”, 20 de noviembre de 1996, Documento CRC/C/58.

Comité de los Derechos del NiÑo, "Orientaciones generales respecto de la forma y el contenido de los informes que han de presentar los Estados partes con 
arreglo al apartado a) del párrafo primero del artículo 44 de la Convención”, 30 de octubre de 1991, Documento $\mathrm{CRC} / \mathrm{C} / 5$.

Cots, Jordi, "Los antecedentes de la Convención. Síntesis de un logro", en: Villagrasa, C.; Ravetllat, I. (Coords.), El desarrollo de la Convención sobre los Derechos del Niño en España, Bosch, Barcelona, 2006, pp. 23-36.

Delgado, Buenaventura, Historia de la infancia, Ed. Ariel, Barcelona, 1998.

DíAZ DE VALDÉs, José Manuel, “Un marco constitucional para los tratamientos médicos de niños, niñas y adolescentes", Revista Chilena de Derecho, 2010, N², p. 271-310.

Documento: "Mensaje de S.E. la Presidenta de la República con el que inicia Proyecto de Ley de Sistema de Garantías de los Derechos de la Niñez", Boletín $\mathrm{N}^{\circ}$ 10.315-18, Cámara de Diputados, Valparaíso, 24 de septiembre de 2015, 39 pp., en línea: https://www.camara.cl/legislacion/ProyectosDeLey/tramitacion. aspx?prmID=10729\&prmBoletin=10315-18.

Dogliotti, Massimo, “Che cosa é l'interesse del minore?", Il Diritto di Famiglia e delle Persone, 1992, N 4, p. 306,

Domínguez, Carmen, "Autonomía en materia de niñez: Tensiones y perspectivas”, en: BARríA, M. (Coord.), Estudios de Derecho Civil XI, Thomson Reuters, Santiago, pp. 101-112.

Donoso, Lorena, "El tratamiento de los datos personales en el sector de la educación”, en: Arrieta, R.; Reusser, C. (Coords.), Chile y la protección de datos personales: ¿están en crisis nuestros derechos fundamentales?, Ediciones Universidad Diego Portales, Santiago, 2009, pp. 57-79.

EscoBAR, Margarita, "La participación ciudadana en Paraguay: análisis a partir de la transición democrática”, Revista Internacional de Investigación en Ciencias Sociales, 2012, Vol. 8, N 1, pp. 119-140.

EspeJo, Nicolás; LATHRop, Fabiola, "Identidad de género, relaciones familiares y derechos de niños, niñas y adolescentes. Comentarios al Proyecto de Ley que reconoce y da protección al derecho a la identidad de género", Revista de Derecho U. Católica del Norte, 2015, Vol. 22, N 2, pp. 393-418.

Estrada, Francisco, "Principios del procedimiento de aplicación de medidas de protección de derechos de niños y niñas", Revista de Derecho Escuela de Postgrado Universidad de Chile, 2015, N 8, pp. 155-184.

GaItán, Lourdes, Sociología de la infancia, Editorial Síntesis, Madrid, 2006.

Galán, Julio César, Responsabilidad civil médica, Civitas, Cizur Menor, 2016.

Gauché, Ximena; Lovera, Domingo, "Identidad de género de niños, niñas y adolescentes: Una cuestión de derechos", Ius et Praxis, 2019, Año 25, № 2, pp. 359-402.

Git, Ana María, ¿Privacidad del menor en internet?, Thomson Aranzadi, Cizur Menor, 2015. 
GonzÁlez, Isabel, "Mediación y solución colaborativa de conflictos familiares. Participación del niño en la solución colaborativa de los conflictos de su familia", Revista Chilena de Derecho de Familia, 2020, Vol. 2, pp. 260-281.

HeRnÁndez, Ana, "La convivencia de ámbitos normativos en la protección de la infancia: reflejo en la Comunidad Autónoma de Aragón", Revista Aragonesa de Administración Pública, 2000, $\mathrm{N}^{\circ}$ 17, pp. 280-301.

Herrera, Paloma, "El derecho a la vida privada y las redes sociales en Chile", Revista Chilena de Derecho y Tecnología, 2016, Vol. 5, N 1, pp. 87-112.

JACQARD, Albert, ¿Una educación sin autoridad ni sanción?, Paidós, Barcelona, 2004.

JeRvis, Paula, "Derechos del titular de datos y habeas data en la Ley 19.628", Revista Chilena de Derecho Informático, 2003, N² 2, pp. 19-33.

Lama, Alejandra, La protección de los derechos de la personalidad del menor de edad, Tirant lo Blanch, Valencia, 2006.

LARRAín, Cristián, "Actos y contratos sobre el derecho a la imagen en el ordenamiento chileno (con referencia al derecho comparado)", Revista de Derecho (Valdivia), 2017, Vol. 30, $\mathrm{N}^{\circ}$ 1, pp. 53-76.

Lathrop, Fabiola, "La protección especial de derechos de niños, niñas y adolescentes en el Derecho chileno", Revista Chilena de Derecho Privado, 2014, $\mathrm{N}^{\circ} 22$, pp. 197-229.

LATHROP, Fabiola, "El derecho a la imagen de niños, niñas y adolescentes en Chile. Una mirada crítica a la luz del Derecho Internacional de los Derechos Humanos y de los estatutos normativos iberoamericanos de protección integral de la infancia y la adolescencia", Revista Chilena de Derecho, 2013, Vol. 40, N 3 , pp. 929-952.

LeÓN, Francisco, "Información y consentimiento informado de menores de edad en Chile", Revista Chilena de Pediatría, 2012, Vol. 83, ํ 2, 2012, pp. 113116.

Linacero, María, Protección jurídica del menor, Montecorvo, Madrid, 2001.

LORENTE, María Cristina, Los derechos al honor, a la intimidad personal y familiar y a la propia imagen del menor, Thomson Aranzadi, Cizur Menor, 2015.

Moreno, Ángela, Intimidad y menores, Centro de Estudios Políticos y Constitucionales, Madrid, 2017.

O'Callaghan, Xavier, Libertad de expresión y sus límites: honor, intimidad e imagen, Revista de Derecho Privado, Madrid, 1991.

Parra, Darío; Ravetllat, Isaac, "El consentimiento informado de las personas menores de edad en el ámbito de la salud", Ius et Praxis, 2019, Año 25, $\mathrm{N}^{\circ}$ 3, pp. 215-248.

PARRA, Darío, "El consentimiento informado de niños, niñas y adolescentes en el ámbito sanitario", en: Domínguez, C. (Coord.), Estudios de Derecho de Familia III, Thomson Reuters, Santiago, 2018, pp. 331-349. 
Picontó, Teresa, La protección de la infancia. Aspectos sociales y jurídicos, Egido, Zaragoza, 1996.

Ramírez, Mónica; Contreras, Sylvia, "Deconstruyendo la noción de infancia asociada a ciudadanía y participación", Revista Internacional de Investigación en Ciencias Sociales, 2014, Vol. 10, N 1, pp. 91-105.

RAVETLlat, Isaac, "El derecho de asociación de niños, niñas y adolescentes", en: Moreno, A.; Schiele, C. (Eds.), Pensamiento Juridico Central, Volumen 2, Tirant lo Blanch, Valencia, 2019, pp. 236-257.

RAVETLLAT, Isaac, "El interés superior del niño/a en los procesos de mediación familiar: Análisis de la realidad chilena”, en: CÉspedes, C. (Dir.), Estudios de Derecho Privado, Thomson Reuters, Santiago, 2019, pp. 3-23.

RAVETLlat, Isaac, "Igual de diferentes: la identidad de género de niñas, niños y adolescentes en Chile", Ius et Praxis, 2018, Año 24, N 1, pp. 397-436.

RavetLlat, Isaac, "Responsabilidad negocial de los actos realizados por personas impúberes: especial referencia a los actos relativos a bienes o servicios propios de su edad, de acuerdo con los usos sociales", en: BARRía, M., (Coord.), Estudios de Derecho Civil XI, Thomson Reuters, Santiago, 2016, pp. 213-224.

Ravetllat, Isaac; Pinochet, Ruperto, "El interés superior del niño en el marco de la Convención Internacional sobre los Derechos del Niño y su configuración en el Derecho Civil chileno", Revista Chilena de Derecho, 2015, Vol. 42, N 3, pp. 903-934.

RavetLlat, Isaac, "Distintos modelos de recepción de los derechos de la infancia y la adolescencia por parte de las legislaciones autonómicas", La Ley Derecho de Familia, 17 de noviembre de 2014, pp. 1-10

ReTAMAL, Alejandra, "Atención de la infancia vulnerable en Chile: diagnóstico sobre su institucionalidad y propuestas de mejoras", en: Retamal, A. (Ed.), Cuadernos de Trabajo del Centro UC de la Familia, N 1, P. Universidad Católica de Chile, Santiago, 2017.

RiziK, Lucía, "La responsabilidad parental y las nuevas tecnologías de la información y la comunicación", en: Mondaca, A.; Aedo, C. (Coords.), Estudios de Derecho de Familia IV, Thomson Reuters, Santiago, 2019, pp. 443-460.

Santamaría, María Luisa, El concepto del interés superior del niño y su dimensión constitucional, Universidad Politécnica de Valencia, Valencia, 2017.

SANTOS, María José, "Menores y derechos de la personalidad. La autonomía del menor", en: DíAz-MARoto, J.; RodríGuez, A. (coords.), El menor ante el derecho en el siglo XXI, Anuario de la Facultad de Derecho, U. Autónoma de Madrid, Madrid, 2011, pp. 63-93.

VARAS, Juan Andrés, "Decisiones vitales y representación parental: fundamento y límites", en: Departamento de Derecho Privado de la Universidad De Concepción (Coords.), Estudios de Derecho Civil IV, Legal Publishing, Santiago, 2010, pp. 337-356. 
Vargas, Macarena; Correa, Paula, "La voz de los niños en la justicia de familia de Chile", Ius et Praxis, 2011, Año 17, N 1, pp. 177-204.

Verhellen, Eugeen, Convention on the Rights of the Child, Garant Publishers, Gent, 1997.

Villagrasa, Carlos, "El derecho de la persona menor de edad hacia una disciplina autónoma desde el Derecho Civil", en: Cabedo, V.; Ravetllat, I. (Coords.), Comentarios sobre las leyes de reforma del sistema de protección a la infancia y la adolescencia, Tirant lo Blanch, Valencia, 2016, pp. 23-48. 